field. Laplace transforms are used to solve linear visco-elastic problems, and creep buckling is discussed. The final chapter gives examples of plate and cylinder analysis for plastic materials.

The book covers a wide range, from classical thermoelasticity to recent developments in viscoelastic theory, and it is pleasing to report that the cross-referencing is good. Parts 2 and 3 are largely self-contained, a fact which will be welcomed by readers concerned with practical aspects of the subject. The numerous references to published work are listed, with comments, in footnotes. I feel that a list of references at the end of each chapter, and a list of symbols at the beginning of the book, would have been helpful. Despite these minor imperfections, the book meets a real need for a reference work in English on this subject, and should prove to be of great value to research and design engineers working in this field.

B. S. OWEN

\section{FLAME PHOTOMETRY}

Flame Photometry

By Prof. John A. Dean. (McGraw-Hill Series in Advanced Chemistry.) Pp. viii +354. (Now York: McGraw-Hill Book Company, Inc.; London : McGraw-Hill Publishing Company, Ltd., 1960.) 89s.

T HE application of flame photometry to the determination of microconstituent elements in biological, mineralogical and related materials has been of continuing interest to chemists since the pioneer work of Lundegaardh on flame excitation, and this interest has increased enormously in the past decade.

The present book by Prof. Dean is a comprehensive account of investigations and of instrumental developments in this field. A general, but adequate introduction dealing with atomization, flame characteristics and the nature of emission spectra is followed by a chapter of particular interest which deals with the use of organic solvents, either added to aqueous solutions to enhance emission by their effect on such physical properties as surface tension and viscosity, or in selective extraction methods to increase the concentration of the test element and reduce interference by extraneous ions.

Following $a$ full description of modern flame photometers, burner systems and photo-sensitive detectors, there is a detailed discussion on interferences axising from flame background, cation and anion enhancement and suppression and spectral coincidences.

Individual chapters are devoted to specific periodic groups giving spectral emission lines and band-heads for various elements, comments on possible interferences and specific applications. Scandium, yttrium and the rare-earths are dealt with, and original spectra of these elements are given. Atomic scientists will notice that beryllium is not mentioned, and that the sensitivity of boron is poor as compared with, for example, the fluorimetric method. Strontium and barium receive detailed treatment.

The principles of atomic absorption spectrophotometry are only briefly discussed, and one hopes that, in view of the interest shown recently in the possibilities of this technique, it will not be long before Prof. Dean deals more fully with this subject.
The later chapters are concerned with the determination of non-metals and with agronomic, clinical and botanical applications. An extensive bibliography of 780 references is given which covers a wide range of materials and analytical procedures.

The book will prove a most valuable working volume for the laboratory and has much to offer the student of spectrophotometry. H. L. BoLTON

\section{INTERIOR BALLISTICS OF ROCKET MOTORS}

Rocket Propellant Handbook

By Boris Kit and Douglas S. Evered. Pp. xiv +354 . (New York and London: The Macmillan Company, Now York, 1960.) 12.50 dollars; 87s. 6d.

Liquid Propellant Rockets

By David Altman, James M. Carter, S. S. Penner and Martin Summerfield. (Princeton Aeronautical Paperbacks, No. 1.) Pp. v+189. (Princeton, N.J. : Princeton University Press ; London : Oxford University Press, 1960.) 2.95 dollare; 24s. net.

Solid Propellant Rockets

By Clayton Huggett, C. E. Bartley and Mark M. Mills. (Princeton Aeronautical Paperbacks, No. 2.) Pp. v+167. (Princeton, N.J. : Princeton Univ эrsity Press; London: Oxford University Press, 1960.) 2.45 dollars; 20s. net.

Solid Propellant Rocket Research

A Selection of Technical Papers based mainly on a Symposium of the American Rocket Society, held at Princeton University, Princeton, January 28, 29, 1960. Edited by Martin Summerfield. (Progress in Astronauties and Rocketry, Vol. 1.) Pp. xix + 692. (New York : Academic Press, Inc. ; London : Academic Press, Inc. (London), Ltd., 1960.) 6.50 dollars.

$\mathrm{R}$ OCKET motors are mechanically simple devices ; that they are nevertheless difficult to design and expensive to develop is due to the fact that present-day quantitative knowledge of the relevant chemical and physical processes is still hopelessly inadequate. The upper limit to the performance of $a$ rocket is relatively easy to predict : only the laws of thermodynamics are required, coupled with the availability of the thermodynamic properties of the propellants, the assumption of equilibrium, and the ability to obtain numerical solutions to a dozen or so simultaneous non-linear algebraic equations. It is the rate processes which present the difficulty : how large the motor must be for a given approach to the maximum performance depends, for example, on rates of chemical reaction, on the fluid mechanics of droplet break-up, and on the interactions between finely divided solids; none of these processes can be accurately computed at present.

In these circumstances, design must proceed mainly by trial and error. The role of theory is reduced to that of investigating models which are no more than caricatures of reality. Such investigations are successful if they correctly predict the trends of the performance variations resulting in changes to the design; for they can then guide the development engineer in the most hopeful directions and assist him to distinguish between major and 